\title{
Equine leptospirosis in tropical Northern Queensland
}

\section{Wangdi, ${ }^{a}$ J Picard, ${ }^{a}$ R Tan, ${ }^{a}$ F Condon, ${ }^{b}$ B Dowling ${ }^{c}$ and B Gummowa, ${ }^{d^{*}}$}

\author{
${ }^{a}$ School of Veterinary and Biomedical Sciences, James Cook University, Townsville, \\ Queensland, Australia; bruce.gummow@jcu.edu.au \\ ${ }^{\mathrm{b}}$ Tableland Veterinary Services Malanda, QLD, Australia \\ ${ }^{\mathrm{C}}$ Townsville Veterinary Clinic, Aitkenvale, QLD, Australia \\ ${ }^{d}$ Faculty of Veterinary Science, University of Pretoria, Pretoria, South Africa \\ ${ }^{*}$ Corresponding author.
}

\section{Abstract \\ Objective}

Determine leptospiral serodiversity, serodominant serovars and prevalence in the horse population of Northern Queensland (NQ), Australia, with special focus on the Atherton Tableland and Townsville-Burdekin regions.

\section{Design}

Cross-sectional survey.

\section{Methods}

Serum samples from 429 horses originating from 172 horse-owning properties in NQ were collected at regional horse shows and veterinary clinics. Samples were analysed using a microscopic agglutination test. Owners were interviewed on potential risk factors associated with leptospirosis.

\section{Results}

Of the 172 properties that submitted samples, horses from 60 properties (35\%, 95\% confidence interval (Cl) 31-39\%) in NQ showed evidence of exposure to one or more serovars of Leptospira at a serum dilution of $1: 100$. The proportion of seropositive properties in the Atherton Tableland and Townsville-Burdekin regions was $25 \%(95 \% \mathrm{Cl} 17-$ $33 \%)$ and $36 \%$ (95\% $\mathrm{Cl} 30-43 \%)$, respectively. In total, 81 horses had titres to a single serovar and the remained had titres to two or more serovars. Although 20 serovars representing 17 serogroups were detected, serovar Arborea was serodominant and detected in horses from 29 properties. Geldings were more at risk (odds ratio 3.3) of being seropositive to serovar Arborea. The detection of serovar Arborea-seropositive horses was strongly associated $(P<0.05)$ with the average annual rainfall each property received and the presence of pigs and sugarcane fields in the vicinity. 


\title{
Conclusion
}

Serological evidence of leptospirosis in horses in NQ indicates that prevalence is high and horses have been exposed to a wide range of serovars.

\author{
Abbreviations \\ AP apparent prevalence \\ $\mathrm{Cl} \quad$ confidence interval \\ Df degrees of freedom \\ MAT microscopic agglutination test \\ NQ Northern Queensland \\ OR odds ratio
}

Leptospirosis is a contagious zoonotic disease affecting domestic animals, wildlife and humans, caused by infection with the pathogenic group of Leptospira spp.[1]The bacteria causes both acute and chronic forms of the disease, with severity of infection depending on the virulence of the organism, host susceptibility and species of host affected.[2] The bacteria are generally transmitted either directly or indirectly from a clinically unaffected maintenance host to an accidental host via ingestion of water, feed and fodder contaminated with urine or by inhalation of urine droplets from an infected maintenance host. Favourable environmental conditions, such as warm temperatures $\left(\approx 25^{\circ} \mathrm{C}\right)$, moisture, neutral soil $\mathrm{pH}[3,4]$ and standing surface water support the survival of Leptospira spp. in the environment for an extended period of time, increasing infection opportunities. A strong association between periods of high rainfall and the incidence of leptospirosis has been noted.[5] Sugarcane fields are thought to contribute to an increase in rodent populations, facilitating the spread of leptospires.[6] Piggeries[7] and cattle herds[8] are proven risk factors for leptospiral infections in cattle and horses, respectively.

Horses, in most cases, are accidental hosts.[9] Most leptospiral infections in horses are asymptomatic, however, clinical syndromes such as fever, anorexia, jaundice and lethargy have been reported.[10] The organism has been shown to be associated with recurrent uveitis,[11] third trimester abortions, still births,[12] liver dysfunction[13] and renal dysfunction.[14] Pomona is the most common serovar involved in equine abortion[12, 15] and recurrent uveitis.[16]

The predominant serovars of Leptospira spp. vary in different countries, with those most frequently reported in serological surveys of horses being Pomona, Icterohaemorrhagiae, Canicola, Grippotyphosa, Hardjo, Australis, Pyrogenes, Tarassovi, Ballum and Autumnalis.[15] In Australia, serovars prevalent in horses differ by geographical location, with Pomona predominating in the tropics and subtropics,[17] and Copenhageni[4] and Ballum[18] predominantly reported in more temperate regions. 
The warm, wet tropical climate of Northern Queensland (NQ), together with various other risk factors, is very conducive for the propagation, maintenance and survival of leptospires in the environment. In addition, Queensland has the most human cases reported in Australia each year.[19] Despite this, few epidemiological studies have been done on leptospirosis in horses in this region. The last known study was done by Slatter and Hawkins [17] and they only looked at horses predominantly from south-east Queensland. The present study was carried out to assess serovar diversity, risk factors and prevalence of leptospirosis in the horse population in NQ.

\section{Materials and methods}

\section{Survey and the study area}

Ethical approval was obtained from James Cook Universities human and animal ethics committees (application nos. H3895 and A1608, respectively) to carry out a cross-sectional study beginning November 2010 through September 2011 to identify and determine the seroprevalence of 22 different serovars of Leptospira (Table 1) in the domestic horse population of $\mathrm{NQ}$, with a special focus on two regions: the Atherton Tableland and Townsville-Burdekin regions. These two regions were chosen as comparative groups for the study because of their distinct geographical conditions. The Atherton Tableland is highland with an annual average temperature of approximately $21^{\circ} \mathrm{C}$ and an average annual rainfall of $1234 \mathrm{~mm}$; Townsville-Burdekin region is lowland with an annual average temperature of approximately $24^{\circ} \mathrm{C}$ and an average annual rainfall of $1123 \mathrm{~mm}$.

Table 1. Apparent prevalence (AP) of specific serovars of Leptospira spp. on 172 properties in Northern Queensland

Northern Queensland

$$
(n=172)
$$

Serovar
AP (\%)(95\%

Cl)
Townsville-Burdekin

$$
\text { (n=66) }
$$

Atherton Tableland

$$
(n=36)
$$

No. of seropositive properties $^{\mathrm{a}}$
No. of seropositive properties $^{\mathrm{a}}$
AP (\%)(95\%

Cl)
No. of seropositive properties $^{\mathrm{a}}$
AP

\begin{tabular}{|c|c|c|c|c|c|c|}
\hline Arborea & 29 & $17(14-20)$ & 10 & $15(11-20)$ & 5 & $14(8-20)$ \\
\hline Topaz $^{b}$ & 18 & $10(8-13)$ & 6 & $9(5-13)$ & 1 & $3(0-6)$ \\
\hline Australis & 11 & $6(4-8)$ & 4 & $6(3-9)$ & 1 & $3(0-6)$ \\
\hline Robinsoni $^{c}$ & 9 & $5(3-7)$ & 3 & $5(2-7)$ & 2 & $6(2-10)$ \\
\hline Djasiman & 8 & $5(3-6)$ & 7 & $11(7-15)$ & 0 & - \\
\hline Pomona & 6 & $3(2-5)$ & 5 & $8(4-11)$ & 1 & $3(0-6)$ \\
\hline Canicola & 6 & $3(2-5)$ & 2 & $3(1-5)$ & 1 & $3(0-6)$ \\
\hline
\end{tabular}
(\%)(95\%

Cl) 
Northern Queensland

( $n=172)$
Townsville-Burdekin

(n=66)
Atherton Tableland

( $n=36)$

Serovar

No. of seropositive properties $^{a}$
AP (\%) $(95 \%$

CI)
No. of seropositive properties $^{a}$
AP (\%) $(95 \%$

CI) No. of seropositive properties $^{a}$ AP (\%) $(95 \%$

CI)

\begin{tabular}{|c|c|c|c|c|c|c|}
\hline Copenhageni & 5 & $3(2-4)$ & 3 & $5(2-7)$ & 1 & $3(0-6)$ \\
\hline Hardjo $^{d}$ & 4 & $2(1-4)$ & 3 & $5(2-7)$ & 1 & $3(0-6)$ \\
\hline Medanensis $^{d}$ & 4 & $2(1-4)$ & 3 & $5(2-7)$ & 1 & $3(0-6)$ \\
\hline Javanica & 4 & $2(1-4)$ & 1 & $2(0-3)$ & 1 & $3(0-6)$ \\
\hline Cynopteri & 4 & $2(1-4)$ & 3 & $5(2-7)$ & 0 & - \\
\hline Kremastos & 3 & $2(1-3)$ & 1 & $2(0-3)$ & 0 & - \\
\hline Panama & 3 & $2(1-3)$ & 1 & $2(0-3)$ & 0 & - \\
\hline Bulgarica & 2 & $1(0-2)$ & 2 & $3(1-5)$ & 0 & - \\
\hline Szwajizak & 2 & $1(0-2)$ & - & - & - & - \\
\hline Tarassovi $^{b}$ & 1 & $1(0-1)$ & 1 & $2(0-3)$ & 0 & - \\
\hline Celledoni & 1 & $1(0-1)$ & 1 & $2(0-3)$ & 0 & - \\
\hline Grippotyphosa & 1 & $1(0-1)$ & 1 & $2(0-3)$ & 0 & - \\
\hline Zanoni $^{c}$ & 1 & $1(0-1)$ & 0 & - & 1 & $3(0-6)$ \\
\hline Batavae & - & - & - & - & - & - \\
\hline Shermani & - & - & - & - & - & - \\
\hline
\end{tabular}

\section{Sample collection and storage}

After owners gave written consent, 429 samples were collected from horses originating from 172 properties in NQ (Figure 1), primarily from Townsville Veterinary Clinic and Malanda Veterinary Clinic. When horses were brought into the clinics for routine clinical 
procedures, owners were briefed on the study and their participation in the study solicited. Apart from these two veterinary clinics, various horse clubs were approached when they had their events and blood samples were obtained from horses of consenting club members. In order to reach a wider cross-section of horses and to get a representative sample from all parts of the region, equine practitioners from more remote areas were also contacted for sample collection. To control confounding and other undue alterations of results, horses that were severely ill, chronically infected or had an underlying immunosuppressive condition were excluded from sampling. This included horses that were presented for emergency evaluation or surgery, had clinical evidence of severe systemic metabolic or cardiovascular disturbance, an infectious disease process, lymphopenia and/or neutropenia or had been diagnosed with an immune-mediated condition. Horses that had not been in the study area for at least 6 months prior to the time of blood collection were also excluded from sampling.

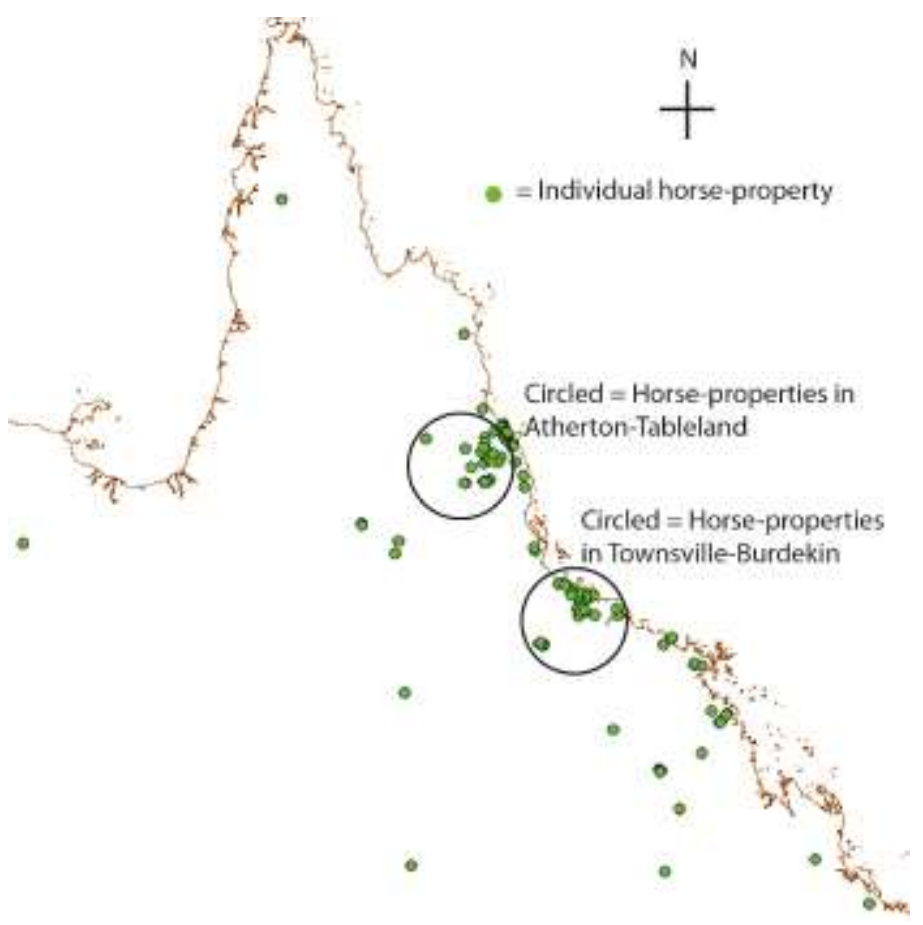

Figure 1. Distribution of properties in Northern Queensland sampled for the presence of Leptospira spp.

Blood samples were collected from the jugular vein of each horse into $10-\mathrm{mL}$ vacutainer tubes. The samples were centrifuged and serum decanted into sterile vials. Sample vials were coded with a unique number for identification and subsequently stored at $-20^{\circ} \mathrm{C}$. Information pertaining to each sample, such as the owner's name and address, and the name, sex, age and breed of the horse as provided by owners in the consent form, was transferred to and maintained in Microsoft Excel 2007 for analysis.

\section{Questionnaire interviews and data collection}

A structured questionnaire was developed and administered to capture information regarding various risk factors for leptospirosis and clinical history (see supporting file S1). The questionnaire was aimed at obtaining information regarding the horse's demographic profile (breed, sex and age), the geographical and environmental factors (location of the 
horse property and the type of agricultural activities prevalent in the locality) and management factors (water sources, other species of animals present in the horse paddock and in the neighbourhood). It also sought information on some common Leptospira-induced clinical signs exhibited by horses, such as ocular disease, kidney disease, high fever, jaundice, abortion and still births. The questionnaire was administered via telephone interview with horse owners after samples had been collected at the veterinary practices, whereas owners whose horses were sampled at local equine events were interviewed at the time of sampling.

Information on the annual average temperature and rainfall that corresponded to each property was obtained from the Bureau of Meteorology, Australia.[20] For properties in remote locations with no meteorological station in the locality, data from the station nearest to the property (not more than $80 \mathrm{~km}$ ) was used.

\section{Serology}

Samples were couriered to the WHO/FAO/OIE Collaborating Centre for Reference and Research on Leptospirosis, Archerfield, Queensland, where the microscopic agglutination test (MAT) was carried out in two stages: (1) screening test to determine the serovar involved and (2) quantitative MAT to determine the serum titre.

All sera were initially screened at a dilution of $1: 50$ against antibodies to 22 serovars (19 serogroups) of leptospires using live antigens. The 22 reference serovars represented those previously isolated in Australia, including the ones commonly involved in human infections, as well as exotic serovars known to occur in neighbouring countries. Every serum sample that gave an agglutination of at least $50 \%$ of the leptospires, compared with positive and negative controls, was considered for the quantitative MAT, in which two-fold serial dilutions of the serum were performed to determine the antibody titre for each of the reactive antigens. The dilutions ranged from $1: 50$ to $1: 6400$. The titre was taken as the highest dilution at which at least $50 \%$ agglutination was recorded. A titre $\geq 1: 100$ was taken as evidence of past exposure to leptospires.[21]

\section{Data analysis}

The MAT results were adjusted for any cross-reactions among different serovars within the same serogroup before being consolidated for further analysis. Apparent prevalence (AP) was calculated using proportions of properties positive to specific serovars. It was assumed that any property with one or more horses reacting positively to one or more of the 22 serovars of Leptospira at serum dilution of $1: 100$ was seropositive to those specific serovars. A serovar-specific AP for each of the 22 serovars of leptospires, together with their $95 \%$ confidence interval $(\mathrm{Cl})$, was calculated and from this the serodominant serovar was determined. Similarly, the AP of leptospires in horse properties specific for the Atherton Tableland and the Townsville-Burdekin regions, together with their $95 \% \mathrm{Cls}$, were also determined and compared.

Different authors have different opinions on the sensitivity and specificity of the MAT. A sensitivity of $92 \%$ and specificity of $95 \%$ [22] were taken into account in the present study 
and the $95 \% \mathrm{Cl}$ for true prevalence of the disease was calculated using formulae adopted from Cameron.[23]

The proportions of seropositive horses to the serodominant serovar in different categories and groups were also calculated. The associations between the seropositivity of horses/properties to the serodominant serovar and various risk factors were analysed using Chi-square and Fisher's exact tests. Odds ratios (OR) for seropositivity of horses/properties to the serodominant serovar according to factors deemed significantly associated in the Chisquare and Fisher's exact tests were modelled using multivariate logistic regression to analyse the size of the effect on the outcome when such factors were present.

A value of $P<0.05$ was considered statistically significant. Statistical analysis was completed in Microsoft Excel 2007, SPSS 11.5 and an online statistical calculator.[24]

\section{Results}

\section{Prevalence of leptospirosis in the horse population of Northern Queensland}

Of the 429 horses originating from 172 properties in NQ, 112 from 60 properties showed evidence of exposure to one or more serovars of Leptospira at a serum dilution of $1: 100$, which means $35 \%$ (95\% Cl 31-39\%) of the sampled properties were seropositive. In total, 81 horses had titres to a single serovar and the remainder had titres to two or more serovars; 20 serovars from 17 serogroups were detected (Table 1). Distribution of the MAT titres ranged from 100 to 6400 , with the modal titre being 100 for 90 samples. Among the 60 infected horse properties, serovar Arborea was the most common, detected on 29 properties, and the second-most common was serovar Topaz, detected on 18 properties, followed by the serovar Australis in 11 properties.

From the Atherton Tableland, 71 horses residing on 36 properties were sampled, of which 11 from 9 properties had titres to one or more serovars of Leptospira. In the TownsvilleBurdekin region, 170 horses residing on 66 properties were sampled and 59 horses on 24 properties had titres to one or more serovars. The proportion of seropositive properties in the Atherton Tableland and Townsville-Burdekin regions was 25\% (95\% $\mathrm{Cl} 17-33 \%$ ) and 36\% (95\% Cl 30-43\%), respectively (Table 1). However, no significant difference could be shown between the two regions (Yates' $\chi^{2}=0.904, d f=1, P=0.3417$ ). Serovar Djasiman may be localised in the Townsville-Burdekin region, because 7 of the 8 properties seropositive to this serovar were in this region.

\section{Analysis of risk factors for association with serovar Arborea}

The seroprevalence of serovar Arborea by demographic, geographic and management factors is presented in Table 2. Seroprevalence differed significantly among the sexes $\left(\chi^{2}=\right.$ $12.0773, \mathrm{df}=2, \mathrm{P}=0.002)$. Being a mare was protective, with a low OR of $0.27(95 \% \mathrm{Cl} 0.11-$ 0.63). In contrast, the odds of a gelding being seropositive were 3.3-fold more than for nongelding $(95 \% \mathrm{Cl} 1.5-7.3)$. Being a stallion was neither protective nor a risk factor (OR 1.1; $95 \% \mathrm{Cl} \mathrm{0.25-4.02)}$ for this serovar. 
Table 2. Distribution of seroprevalence for serovar Arborea by demographic, geographic and management factors

$\begin{array}{lll}\text { Variable } & \text { No. of positive horses } \\ & \text { Titre } \geq 1: 100 \text { AP (\%) }\end{array}$

Sex

Female

Stallion

Gelding

Age (years)

$\leq 5$

6-15

$\geq 16$

Breed

Australian Stockhorse

Quarter Horse

Thoroughbred

Crossbred

Other

Temperature $\left({ }^{\circ} \mathrm{C}\right)$

$\leq 23$

$>23$

Av. annual rainfall ( $\mathrm{mm}$ )

$<1000$

1000-2000

$>2000$

Sugarcane fields in locality
204

32

188

78

273

77

11

14.29

91

9.89

65

5

7.69

119

7

5.88

60

5

8.33

85

10

11.76

37

6

16.22

133

23

17.29

49

4

94

15

15.96

27

10

37.04 


\begin{tabular}{|c|c|c|c|}
\hline & & No. of positive & horses \\
\hline Variable & No. of horses tested & & \\
\hline & & Titre $\geq 1: 100$ & AP (\%) \\
\hline Yes & 34 & 11 & $32.35^{\mathrm{a}}$ \\
\hline No & 123 & 17 & 13.82 \\
\hline Other species of anima & & & \\
\hline Cattle & 102 & 18 & 17.65 \\
\hline Pigs & 42 & 13 & $30.95^{b}$ \\
\hline Dogs & 96 & 15 & 15.63 \\
\hline Macropods & 64 & 9 & 14.06 \\
\hline Water source & & & \\
\hline Municipal water & 46 & 8 & 17.39 \\
\hline Bore water & 61 & 9 & 14.75 \\
\hline Creek water & 30 & 7 & 23.33 \\
\hline Dam water & 30 & 7 & 23.33 \\
\hline
\end{tabular}

${ }^{a}$ Yates' Chi-square $=5.042, \mathrm{df}=1, \mathrm{P}=0.0247 .{ }^{\mathrm{b}}$ Yates' Chi-square $=5.688, \mathrm{df}=1, \mathrm{P}=0.0171 . \mathrm{AP}$, apparent prevalence.

The age of sampled horses ranged from 0 to 34 years, with a median of 9.5 years old. Horses were considered 0 years old in the year of birth. Although seroprevalence of serovar Arborea increased with age, no significant association was observed between seropositivity and age groups $\left(\chi^{2}=3.9092, d f=2, P=0.142\right)$. In addition, no breed-related difference could be observed $\left(\chi^{2}=2.4744, d f=4, P=0.649\right)$.

Horses comprising different breeds were categorised as 'crossbred' and those breeds not represented with enough numbers to be considered as a category were grouped as 'other'.

Annual average temperatures on the horse properties included in the survey ranged from $19.9^{\circ} \mathrm{C}$ to $26^{\circ} \mathrm{C}$, with a median of $23.9^{\circ} \mathrm{C}$. Horse properties were grouped into two categories based on their annual average temperature $\left(\leq 23^{\circ} \mathrm{C}\right.$ and $\left.>23^{\circ} \mathrm{C}\right)$ and the proportion of seropositive properties calculated for both. No association between the seropositivity of properties to serovar Arborea and the annual average temperatures on the properties was detected (Yates' $\chi^{2}=0.024, d f=1, P=0.8776$ ).

Average annual rainfall received by the 172 properties included in the study ranged from 448 to $4274 \mathrm{~mm}$, with a median of $1143 \mathrm{~mm}$. High rainfall was significantly associated with 
the proportion of properties seropositive to serovar Arborea $\left(\chi^{2}=10.4375, \mathrm{df}=2, \mathrm{P}=\right.$ $0.005)$. Chi-square analysis also revealed that properties with sugarcane fields in the locality had a significantly higher seroprevalence (Yates' $\chi^{2}=5.042, \mathrm{df}=1, \mathrm{P}=0.0247$ ) compared with those that did not. Multicollinearity was observed between rainfall and sugarcane fields in the multivariate logistic regression analysis and statistical significance in the resultant ORs was lacking. Hence, the multivariate logistic regression analysis was computed limiting one of these factors at a time and the results are presented in Tables 3 and 4.

Table 3. Multivariate logistic regression analysis of the model-limiting availability of sugarcane fields in the vicinity of properties

\begin{tabular}{|c|c|c|c|c|}
\hline Variable & OR (95\% Cl) & Coefficient & SE & $P$ value \\
\hline Constant & - & -2.857 & 0.594 & $<0.001$ \\
\hline Pigs in the vicinity & $3.9(1.6-9.5)$ & 1.356 & 0.459 & 0.003 \\
\hline \multicolumn{5}{|l|}{ Rainfall (mm) } \\
\hline$<1000$ & 1.0 & - & - & - \\
\hline $1000-2000$ & $2.4(0.7-8.0)$ & 0.867 & 0.617 & 0.160 \\
\hline$>2000$ & $6.1(1.6-24.0)$ & 1.815 & 0.697 & 0.009 \\
\hline
\end{tabular}

Table 4. Multivariate logistic regression analysis of the model-limiting amount of rainfall each property received

Variable OR $(95 \% \mathrm{Cl})$ Coefficient SE P value

$\begin{array}{lllll}\text { Constant } & 0.102 & -2.286 & 0.338<0.001\end{array}$

Pigs in the vicinity $3.8(1.5-9.2) 1.329 \quad 0.454 \quad 0.003$

Sugarcane fields $3.2(1.3-8.0) \quad 1.158 \quad 0.471 \quad 0.014$

$\mathrm{Cl}$, confidence interval; OR, odds ratio; SE, standard error.

The presence of cattle, pigs (including feral pigs), dogs (including dingoes) and macropods (kangaroos and wallabies) on the property or in the neighbourhood, and their influence on the status of the property being seropositive to serovar Arborea, were also analysed. The presence of pigs in the paddock or in the neighbourhood had a significant influence on the status of the property being seropositive to this serovar (Yates' $\chi^{2}=5.688, d f=1, P=$ 0.0171). Multivariate logistic regression analysis revealed that properties with pigs in the vicinity were approximately 3.9-fold more likely to be seropositive to serovar Arborea than those without pigs in the vicinity.

No significant association could be observed between seropositivity and the source of water for the sampled horses, although the proportion of seropositive properties among those that used creek and dam water was higher. 


\section{Clinical history and association with serovar Arborea}

In the questionnaire, owners were asked if their horses had exhibited signs related to leptospirosis. Analysis of the data on ocular disease, high fever, abortion and still births did not show any association of these signs with seropositivity to serovar Arborea.

\section{Discussion}

\section{Seroprevalence study}

In the present study, seroprevalence was computed in terms of the sampling unit 'property', not the individual horse, because of clustering of horses on properties. It is tempting to say that the overall seroprevalence of leptospirosis in the horse population of NQ was 35\%. However, this figure must be interpreted with caution because of potential bias. Most of the samples came from the eastern coastal areas of NQ, where leptospiral infection is endemic, and there were very few or no samples from the western areas.

The panel of antigens used for the MAT contained 22 serovars representing 19 serogroups. Of the 22 serovars used, 20 from 17 serogroups were detected in this survey. The major serovars, in order of their decreasing seroprevalence were Arborea (17\%), Topaz (10\%), Australis (6\%), Robinsoni (5\%) and Djasiman (5\%). Seroprevalence of the remaining serovars used in the survey as antigen was $\leq 3 \%$ each, with the exception of serovars Batavae and Shermani, which were not detected. In this study, many horses had titres to multiple serovars. Although some cases were consistent with known cross-reactions and were adjusted, it was assumed that the remainder represented multiple infections. Further, it was difficult to make specific comparisons of the findings between studies, because the cut-off titre, number and representative serovars used in the panel of antigens in the MATs differed from study to study. Previous surveys of horses in Australia have detected and reported the prevalence of the serovars Pomona, Tarassovi, Hardjo, Ballum, Autumnalis, Zanoni, Canicola, Copenhageni, Australis, Grippotyphosa and Bataviae.[4, 17, 18] Some of the serovars that the current survey detected, but not reported in earlier studies, were Arborea, Topaz, Robinsoni, Djasiman, Medanensis, Javanica, Cynopteri, Kremastos, Panama, Bulgarica, Szwajizak and Celledoni. This confirms that horses in NQ have been exposed to various strains of leptospires. More representative samples were obtained from the Atherton Tableland and Townsville-Burdekin regions. Hence, the reported seroprevalence of leptospirosis in the horse population in these two regions of NQ is more reliable.

The Atherton Tableland is cool highland, whereas the Townsville-Burdekin region is warmer lowland. Warm, wet environmental conditions support the survival of leptospires in the environment for longer periods, increasing the opportunities of exposure.[4, 5] As expected, seroprevalence was lower in the Atherton Tableland (25\%) than in the Townsville-Burdekin region (36\%), but the difference was not statistically significant. However, there was a noticeable difference in the diversity of serovars detected in the two regions. Of the 22 serovars tested, antibodies to 18 serovars were detected in the Townsville-Burdekin region. Serovar Arborea was serodominant and detected on $15 \%$ of properties. In the Atherton Tableland, antibodies to only 11 serovars were detected and Arborea was still serodominant, being detected on $14 \%$ of properties. 


\section{Serodominant serovar Arborea and other serovars of significance}

This study revealed that the serodominant serovar affecting the horse population in NQ was Arborea. The antibody titres of the horses seropositive to this serovar ranged from $1: 100$ to $1: 800$, and $84 \%$ of the seropositive cases had low titres $(\leq 200)$, suggesting this serovar may not cause significant clinical disease in horses. Interestingly, none of the earlier studies of horses in Australia have reported this serovar, probably because it was assumed not to affect horses and was not included in the panel of antigens used. In the seroprevalence study of horses from south-east Australia conducted by Swart et al.,[18] serovar Ballum was predominant with $15.1 \%$ prevalence. Serovars Ballum and Arborea both belong to the same serogroup (Ballum) and they are known to react similarly in the MAT.[25] However, serovar Ballum has not been isolated from any source in Australia, whereas serovar Arborea was isolated from rodents at two sites in Queensland.[25] This could mean that serovar Arborea cross-reacted with serovar Ballum in the study conducted by Swart et al.[18] and that serovar Arborea was circulating in horse populations long before this particular serovar was detected in humans in 1998.

A rising trend of emergence of serovar Arborea was observed in the human health sector in 2004. $[19,25]$ In the public health sector, leptospirosis notifications in Australia in 2008 and 2009 listed serovar Arborea as the most common, constituting $21.2 \%$ and $29.4 \%$, respectively, of the total notifications. The majority of the notifications ( $92 \%$ for 2008 and 79\% for 2009) was from Queensland.[19] The concurrent finding of large number of horses in the same state reacting to this serovar suggests that perhaps, by monitoring seroconversion, horses may be used as sentinels to predict leptospirosis incidence in humans in NQ. The finding also suggests that there may be local epidemiological cycles that are not yet fully understood. It is difficult to infer beyond what has been stated, partly because of the lack of similar studies in horses after 1982 and because the serovar Arborea only became evident in the public health domain in 1998.[25] A more detailed study of this serovar in horses from a public health perspective might clarify the issue.

NQ is known for cattle production, but the low prevalence (2\%) of reactions to serovar Hardjo in horses contrasts markedly with the reported high prevalence of $49.9 \%$ and $15.8 \%$ in unvaccinated cattle of the Atherton Tableland[26] and central Queensland,[27] respectively. Similarly, the seroprevalence of serovar Pomona was only $3 \%$ against a prevalence of $18.5 \%$ in pigs[28] and $30.3 \%$ in horses[17] from Queensland. From this observation, it appears that cattle and pigs are not the respective sources of Hardjo and Pomona infection in horses. It is also possible that the infection rate in those two species has decreased over the past decade because of better vaccination strategies, coverage and efficacy of the vaccines used.[29]

\section{Risk factors and their association with serovar Arborea}

\section{Demographic factors}

In this study, mares had the lowest seroprevalence of 3.9\% and stallions and geldings had $9.4 \%$ and $13.8 \%$, respectively, a statistically significant difference. Although some 
eccentricity in the data for stallions was expected because of the small sample size, no obvious explanation could be ascertained for what was observed in mares and geldings.

A trend towards increasing seroprevalence with increasing age has been previously demonstrated for different serovars of Leptospira.[30,31] Similarly, this study showed that seroprevalence to serovar Arborea increased with age. However, the difference in seroprevalence between different age groups was not statistically significant.

Seroprevalence to serovar Arborea did not vary according to breed. In contrast, Jung[21] reported a significantly lower seroprevalence in Thoroughbred horses used for racing in Korea, because of the high level of management and care associated with the racehorses. Most of the Thoroughbred horses sampled in the present study were not used for racing, but rather for breeding and equestrian events such as dressage and polo. There were no management differences between this breed and other breeds, hence the absence of difference in seroprevalence.

\section{Geographic and environmental factors}

The observed annual average temperature range $\left(19.9-26^{\circ} \mathrm{C}\right)$ in NQ did not have significant influence of its own on the seropositivity of properties to serovar Arborea. However, increased moisture content in the environment within this temperature range had a strong influence.

There was a wide variation among the properties in NQ with regard to the average annual rainfall each property received. Some properties in the eastern coastal plains had an average annual rainfall as high as $4274 \mathrm{~mm}$, while those in the interior parts had as low as $448 \mathrm{~mm}$. The proportion of seropositive properties increased with increased rainfall. The odds of a property with an average annual rainfall $>2000 \mathrm{~mm}$ becoming seropositive to serovar Arborea was 6.1-fold higher than for properties with an average annual rainfall $<1000 \mathrm{~mm}$. The association identified in this study is also supported by previous observations made in cattle,[32] dogs[5, 6] and humans.[25] A plausible explanation could be that infected animals, including horses,[12] shed the organism into the environment, contaminating soil and water, which become the sources of infection to other susceptible animals. High rainfall could provide a suitable condition for leptospires to survive in a contaminated environment for extended periods, ensuring a sustained source of infection to susceptible host populations, including horses.

Sugarcane fields are believed to harbour rodents, $[6,25]$ especially rats, which are one of the main reservoirs for serovar Arborea. We found that the presence of sugarcane fields in the locality had a significant influence on properties being seropositive to this serovar. The odds of a property with sugarcane fields in the locality becoming seropositive to serovar Arborea was 3.2-fold more than for those located distant to sugarcane fields.

Although collinearity was observed between rainfall and the presence of sugarcane fields, given the prior established evidence of both factors playing an important role in the epidemiology of leptospirosis, neither could be eliminated for this study. 


\section{Management factors}

The proportion of properties seropositive to serovar Arborea was significantly higher for those that ran horses together with pigs (including those visited by feral pigs) and those with pigs in the neighbourhood compared with properties without pigs in the vicinity. It is difficult to explain this association because pigs are naturally adapted to serovar Pomona[28] and not Arborea. Pigs have poorly developed body heat regulatory mechanisms,[33] so they frequently wallow in mud and water to keep cool. Because serovar Arborea was strongly associated with high rainfall, pigs could be exposed to it through mud and flood water and therefore they cannot be ruled out as potential carriers.

The different sources of water did not have any influence on the status of the property being seropositive to the serovar Arborea. Although the proportion of seropositive properties among those that used creek and dam water was higher compared with other sources, statistical significance was lacking.

\section{Clinical signs}

High fever (during the acute phase), uveitis, kidney and liver failure, abortion and still births are notable reported clinical signs of leptospirosis in horses. Although most of the literature have associated these pathological conditions with serovar Pomona, analysis of the limited data in this study showed serovar Arborea was not associated with any of the reported clinical signs of leptospirosis in horses, suggesting that it may not cause clinical disease in horses.

\section{Acknowledgments}

The authors thank Professor Scott Craig, Mary-Anne Burns and their team, WHO/FAO/OIE Collaborating Centre for Reference and Research on Leptospirosis at Archerfield, Queensland, for running the laboratory analysis of the samples at a reduced cost. Thanks also to Professor Robert Hedlefs for providing equine demographic data for Queensland and also for his help in acquiring serum samples. The authors also acknowledge the assistance received from Dr James Staunton (Moranbah Veterinary Clinic), Dr Andrew Easton (Kuranda Veterinary Surgery), Dr Cameron O'Neil (Valley Veterinary Clinic), Dr Josh Berryman (North West Veterinary Clinic) and all the staff and students of James Cook University who were directly or indirectly involved in sample collection.

\section{References}

1. Verma A, Artiushin S, Matsunaga J, Haake DA, Timoney JF. LruA and LruB, novel lipoproteins of pathogenic Leptospira interrogans associated with equine recurrent uveitis. Infect Immun 2005;73:7259-7266.

2. Hajikolaei MRH, Masood G, Mohammad H, Golamreza A. Comparison of leptospiral infection in the horse and donkey. $B$ Vet Inst Puławy 2005;49:175-178.

3. Babudieri B. Animal reservoirs of leptospires. Ann NY Acad Sci 1958;70:393-413.

4. Dickeson D, Love DN. A serological survey of dogs, cats and horses in south-eastern Australia for leptospiral antibodies. Aust Vet J 1993;70:389-390. 
5. Ward MP. Seasonality of canine leptospirosis in the United States and Canada and its association with rainfall. Prev Vet Med 2002;56:203-213.

6. Miller RI, Ross SP, Sullivan ND, Perkins NR. Clinical and epidemiological features of canine leptospirosis in North Queensland. Aust Vet J 2007;85:13-19.

7. Gummow B, Myburgh JG, Thompson PN, van der Lugt JJ, Spencer BT. Three case studies involving Leptospira interrogans serovar pomona infection in mixed farming units. J S Afr Vet Assoc 1999;70:29-34.

8. Ellis WA, Bryson DG, O'Brien JJ, Neill SD. Leptospiral infection in aborted equine foetuses. Equine Vet J 1983;15:321-324.

9. Frellstedt L. Equine recurrent uveitis: a clinical manifestation of leptospirosis. Equine Vet Educ 2009;21:546-552.

10. Roberts SJ, York CJ, Robinson JW. An outbreak of leptospirosis in horses on a small farm. J Am Vet Med Assoc 1952;121:237-242.

11. Brandes K, Wollanke B, Niedermaier G, Brem S, Gerhards H. Recurrent uveitis in horses: vitreal examinations with ultrastructural detection of leptospires. J Vet Med A Physiol Pathol Clin Med 2007; 54:270-275.

12. Donahue JM, Smith BJ, Poonacha KB, Donahoe JK, Rigsby CL. Prevalence and serovars of leptospira involved in equine abortions in central Kentucky during the 1991-1993 foaling seasons. J Vet Diagn Invest 1995;7:87-91.

13. Barsoum IS, Botros BA, Morcos MB. Equine leptospirosis with some clinical observations. Ann Rech Vet 1978;9:115-118.

14. Hatazoe T, Hobo S, Yamashita N, Komatsu K, Misumi K. Case study of equine leptospirosis associated with renal failure. J Jpn Vet Med Assoc 2009;62:303-307.

15. Szeredi L, Haake DA. Immunohistochemical identification and pathologic findings in natural cases of equine abortion caused by leptospiral infection. Vet Pathol 2006;43:755761.

16. Faber NA, Crawford M, LeFebvre RB et al. Detection of Leptospira spp. in the aqueous humor of horses with naturally acquired recurrent uveitis. J Clin Microbiol 2000;38:27312733.

17. Slatter DH, Hawkins CD. Prevalence of leptospiral titres in normal horses. Aust Vet J 1982;59:84-86.

18. Swart KS, Calvert K, Meney C. The prevalence of antibodies to serovars of Leptospira interrogans in horses. Aust Vet J 1982;59:25-27.

19. Smythe L, Craig S, Burns MA, Dohnt M. National leptospirosis surveillance: report number 18 (January-December 2009). WHO/FAO/OIE Collaborating Centre for Reference and Research on Leptospirosis, Queensland Health Scientific Services, Coopers Plains. 2009. http://www.health.qld.gov.au/qhcss/lep_rep.asp. Accessed August 2011.

20. Bureau of meteorology, Commonwealth of Australia. Climate statistics for Australian sites. 2011. http://www.bom/gov.au/. Accessed October 2011.

21. Jung BY, Lee KW, Ha TY. Seroprevalence of Leptospira spp. in clinically healthy racing horses in Korea. J Vet Med Sci 2010;72:197-201.

22. Hickey PW. Pediatric leptospirosis workup. WebMD professional. 2010.

http://emedicine.medscape.com/article/965698-workup. Accessed November 2011.

23. Cameron AR. Appendix B: statistical equations. In: Survey toolbox for livestock diseases: a practical manual and software package for active surveillance in developing countries. Australian Centre of Industrial Agricultural Research, 1999;54:295-307. 
24. Pezzullo JC. Web pages that perform statistical calculations. 2010.

http://statpages.org/JCPhome.html. Accessed October 2011.

25. Slack AT, Symonds ML, Dohnt MF, Smythe LD. The epidemiology of leptospirosis and the emergence of Leptospira borgpetersenii serovar Arborea in Queensland, Australia, 19982004. Epidemiol Infect 2006;134:1217-1225.

26. Norton JH, Tranter WP, Campbell RS. A farming systems study of abortion in dairy cattle on the Atherton Tableland. 2: the pattern of infectious diseases. Aust Vet J 1989;66:163167.

27. Black PF, Corney BG, Smythe LD et al. Prevalence of antibodies of Leptospira serovars in beef cattle in central Queensland. Aust Vet J 2001;79:344-348.

28. Elder JK, Ward WH. The prevalence and distribution of leptospiral titres in cattle and pigs in Queensland. Aust Vet J 1978;54:297-300.

29. Marshall RB, Manktelow BW. Fifty years of leptospirosis research in New Zealand: a perspective. NZ Vet J 2002;50:61-63.

30. Baverud V, Gunnarsson A, Engvall EO, Franzen P, Egenvall A. Leptospira seroprevalence and associations between seropositivity, clinical disease and host factors in horses. Acta Vet Scand 2009;51:15.

31. Lees VW, Gale SP. Titers to Leptospira species in horses in Alberta. Can Vet J. 1994;35:636-640.

32. Carroll AG, Campbell RS. Reproductive and leptospiral studies on beef cattle in central Queensland. Aust Vet J 1987;64:1-5.

33. Ingram DL. Evaporative cooling in the pig. Nature 1965;207:415-416. 